dents generally pay a significant premium for the privilege of studying the Western curriculum.

In some cases, the Western institution is integrally involved with all aspects of the educational program. In others, programs are "franchised," and there is little direct supervision or involvement by faculty from the "home" university. In a way, such operations are quite similar to McDonalds-an foreign vendor pays for using a "brand name" and must deliver a product designed abroad to local customers. Unlike McDonalds, quality control in the educational marketplace is spotty.

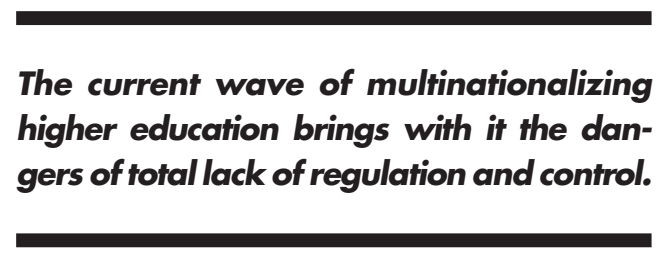

Increasingly, foreign educational providers are setting up shop in Asia and Eastern Europe without working with a local educational institution. Often, a business firm or entrepreneur invests resources to start an educational institution, and contracts with a Western university or other institution to provide the service and to award the degree. In some cases, a foreign institution will simply open a program. Again, there are few controls concerning quality, financial arrangements, or other details.

These are a few examples of the growing globalization of higher education. This phenomenon has many positive aspects. It helps serve rapidly growing demand for access to higher education. It stimulates cross-national educational innovation. It prepares students for work in a global economy. Yet, the multinationalization of higher education creates many challenges. Among them are;

- quality control-how can offshore providers be regulated and how can quality be ensured?

- information-who can tell which are worthwhile programs offered by reputable institutions and which are of low quality, sold just to make a quick profit?

- fit-do the programs meet a local need and do they contribute to the higher education system, and how do they related to local institutions?

- costs and benefits-are the programs worth what is charged for them?

These questions are difficult to answer. Measuring educational outputs is difficult in the best of circumstances. Fostering international cooperation and innovation in higher education is a good thing, and imposing too many controls may stifle new ideas. Yet, the current wave of multinationalizing higher education brings with it the dangers of total lack of regulation and control. It is a bad idea, in education at least, to permit caveat emptor to dominate.

\section{Jesuit Education: An International History}

\section{William B. Neenan, S.J.}

William B. Neenan, S.J. is vice president and special assistant to the president at Boston College. Address: 100 College Rd., Boston College, Chestnut Hill MA 02467 USA.

$\mathrm{T}$ he Society of Jesus early on has regarded education as a principal apostolate. In 1548 , only eight years after its founding, Ignatius Loyola, the first superior general, ordered a college to be opened in Messina, Sicily. Within a half century, several hundred Jesuit colleges had been established across Europe as well as in Lima, Mexico City, and Manila. Ignatius insisted that his followers be prepared on a moment's notice to go wherever they might better serve God. The age of discovery provided them with the occasion to do just that.

To trace this history, it is useful to divide Jesuit educational efforts into three eras: the age of discovery (15481763); the restoration of the Society of Jesus (1814-1960); and the age of globalization (after 1960). I will identify a few of the principal developments in each of these periods and conclude by identifying some challenges that face Jesuit education at the close of the 20th century.

Age of Discovery (1548-1763)

The Portuguese, Spanish, and French explorers of the 16th and 17 th centuries were often accompanied by Jesuits. These Jesuits exhibited the Ignatian insight that "God is to be found in all things," in their remarkable sensitivity to the languages, history, literature, and science of people who were often encountering Europeans for the first time. In addition to establishing their schools, Jesuits contributed significantly to the development of indigenous cultures. In the early 17 th century, Jesuit schools were the earliest disseminators of a literary culture in the Philippines through theatrical productions; and in the Paraguayan Reductions (1610-1767).

Jesuit scientists and mathematicians of the 16th and 17 th centuries, such as Matteo Ricci, interacted with Chinese scholars in the courts of the emperors. But this promising engagement between East and West was ill-starred. When the Chinese Rites, developed by Jesuits to accommodate Catholic liturgical practices to Chinese customs, were condemned by Roman authorities, Jesuit influence in the emperors' court cooled, and we are left with one of the great "what ifs" in history.

Then, in 1763, the Society of Jesus was suppressed by the Holy See. This action was taken under pressure from the Enlightenment rulers of Portugal, Spain, and Franceaided and abetted by the incompetence and venality of some Jesuit superiors. Thus ended two centuries of Jesuit educa- 
tional activity with the age of discovery receding and the Enlightenment and the spirit of revolution assuming center stage in Europe.

\section{Restoration of the Society of Jesus (1814-1960)}

The Society of Jesus was restored by the Holy See in 1814 . The world the restored Society entered had been greatly altered during its 41-year hibernation. Metternich and his allies were attempting to reestablish the political and social structure of prerevolutionary Europe. In many ways, these reactive and conservative maneuvers on the political stage of Europe are reflected in the Jesuit educational efforts in the 19th century. Jesuit writers and scholars were often fearful and cautious, perhaps understandably so considering the anticlerical dispositions of the major European powers. But whatever the reason, Jesuit educators of the 19th century did not exhibit the verve and imagination that had characterized their predecessors in the presuppression Society.

There were, however, notable accomplishments during this period. Jesuit colleges were gradually reestablished worldwide, and as before, they became the cultural centers of their communities. "The Schoolmasters of Europe," of the 17th and 18th centuries, however, had an especially troubled time in their old schoolyard in the 19th century. French anticlerical governments and the Prussian Bismarck expropriated Jesuit property and expelled them. Many exiled German Jesuits settled in the United States and established colleges across the Midwest.

In fact, the most notable developments of Jesuit education at this time occurred in the United States. Georgetown University opened its doors in 1789 as the first Catholic college in the United States, coming under Jesuit auspices in 1814. During the next two centuries, Jesuit education in the United States prospered. In 1999 there are 30 Jesuit institutions of higher education and 46 high schools enrolling 250,000 students.

Even though education remains the principal apostolate of the Society of Jesus, Jesuit schools no longer occupy the paramount cultural position they often held in many countries in the 16th, 17 th and 18 th centuries. The termination of government support, the growth of state-supported education, and simply the increased numbers being educated have meant that the prominent position enjoyed by Jesuit schools in those centuries is simply unsustainable. In the 20 th century Jesuit schools represent only one of a number of educational options.

\section{Age of Globalization (1960-the present)}

There have been two notable developments in Jesuit colleges in recent years: an increased emphasis on promoting social justice and on their Catholic and Jesuit nature. The former stems from the Thirty-second General Congregation of the Society of Jesus (1972-73), in which Jesuits are directed to identify with the poor and work to reform unjust social structures. A Jesuit's faith in God should manifest itself in striving for a just society that meets basic human needs for all.

\section{Jesuit scientists and mathematicians of the 16th and 17th centuries, such as Matteo Ricci, interacted with Chinese scholars in the courts of the emperors.}

Nowhere has the price paid to carry out this decree been higher than at the Universidad de Centroamericana, where in 1989 six Jesuit professors, their housekeeper, and her daughter were assassinated by the military government for the university's efforts on behalf of the dispossessed of El Salvador. Today, Jesuits can be found working directly with refugees, the unemployed, and the homeless, but the Jesuit response to the directives of various General Congregations is also increasingly carried out in Jesuit colleges.

Jesuit colleges are now entering into the mainstream of higher education, in competition with the major secular universities. In doing so they must sometimes address an attitude that an institution cannot be both Catholic and a university. Either out of a growing awareness in society that religious inspiration does bring a valued dimension to education and/or out of a sense of urgency occasioned by the declining number of Jesuits—but for whatever reason many Jesuit institutions are making significant efforts to reassert their unique traditions, convinced that rather than being problematic Catholic and Jesuit values enhance their contributions to higher education

Any generalization regarding Jesuit education must be adapted to fit the widely varying contexts of a particular institution. In 1999, there are worldwide 78 colleges or universities under some form of Jesuit sponsorship, as well as another 100 seminaries and Jesuit residences within a collegiate setting that fall under the umbrella of "Jesuit international higher education." Together, they enroll over a half million students.

Thirty of these institutions are in India, another 30 in the United States, 28 in Central and South America, with the remainder distributed across 35 other nations. It would be inaccurate to say that a network of Jesuit colleges exists. There is, however, a growing sense of solidarity and active cooperation among them. Jesuit schools in Central and South America have recently formed the Association of Jesuit Universities in Latin America, to promote faculty and student exchanges, coordinate their research efforts on poverty and economic development, and serve as a clearing house for ideas. 


\section{Three Challenges}

The 178 Jesuit institutions face many challenges. Three are more or less common to all. The first is that the number of Jesuits worldwide is declining. Currently 4,561 Jesuits work in Jesuit institutions of higher education, along with 74,750 non-Jesuit faculty colleagues. This ratio in itself does not mean that these institutions are in danger of losing their Jesuit character. For decades, many "Jesuit" institutions have been staffed primarily by non-Jesuit colleagues who are dedicated to the Jesuit character of their schools. But a future with notably fewer Jesuit educators is a matter of serious concern for the future of Jesuit education.

Establishing financial stability is a second challenge for all Jesuit colleges-even though the seriousness of this challenge varies greatly from school to school. In some instances, schools receive government subventions; a few that rely on tuition and private donations are relatively secure, while many, especially those that serve primarily low-income students, face severe constraints. This problem is not a new one and is shared with other institutions of higher education, whether public or private.

\section{Today, Jesuits can be found working directly with refugees, the unemployed, and the homeless, but the Jesuit re- sponse to the directives of various Gen- eral Congregations is also increasingly carried out in Jesuit colleges.}

A third challenge is unique to religious institutionsestablishing the appropriate relationship between an institution and the local Roman Catholic bishop and the Holy See. The issue has come to the fore recently with the 1990 Holy See document, "Ex Corde Ecclesiae," and subsequent attempts by national groups of bishops to develop specific norms to implement general principles governing the college-hierarchical church relationship. Jesuit universities, specifically their theology faculties, are obviously "Catholic" in some sense. At issue is how this fact is to be understood juridically in such different locales as Omaha, Seoul, Madras, and Managua. How is the freedom a university must enjoy from inappropriate interventions-whether by a bishop, or a benefactor, or a government functionary, for that matter-to be reconciled with the Church's legitimate concern that theology taught under the rubric of "Catholic" be consistent with the Catholic tradition? The answer to that question undoubtedly requires dialogue and mutual trust.

\section{Continuous Learning: The Killer Application of Technology}

\section{Jack Wilson}

Jack Wilson is professor of physics and engineering science, and serves as dean of faculty at Rensselaer Polytechnic Institute, Troy, New York, USA. He is a founder of Interactive Learning International (ILINC) and serves as chairman of the board.

$\mathrm{T}$ he killer application of computing is learning. The computer has evolved from a wonderful calculator to a great typewriter, to a fancy television, and with the advent of the World Wide Web, to a four-color sales brochure, which is where we are today. To move forward and fully realize the promise of technology, we need creativity and courage, as well as a deep understanding of the way we learn and retain information.

At a recent meeting of the American Society of Engineering Education, Christopher Galvin, president of Motorola, declared that the company no longer wanted to hire engineers with four-year degrees. Instead, he said, they needed employees with 40-year degrees. Motorola is representative of the many companies where continuous learning is crucial, making learning the killer app of this generation of computing.

The traditional model of distance learning has merely pushed back classroom walls, using a lecture-based format with one-way transmission and no interaction. This is the mainframe model, akin to the old-style mainframe computer with several dumb computers hooked up to it. We need to progress instead to a client server model, wherein every student and every faculty member is a resource, comprising a rich interacting community of learners. The challenge is how to use technology to create such a collaborative learning environment.

\section{Curriculum Reform at Rensselaer}

Over the last seven years, Rensselaer has been reforming its undergraduate education in science, mathematics, engineering, and technology in an effort to improve the quality of its education and incorporate technology into its curriculum. Minimizing costs has also been a goal. To that end, merely bolting technology on top of what already is being used, which invariably costs more, has been avoided whenever possible. Instead, technology is being used to change the learning process itself. This change should by no means reduce the need for faculty-unless you accept the mainframe model of education, in which case faculty could be replaced by a CD-Rom or Web site, and one star professor could teach every student in the country. In the collaborative learning model, however, the aim is to help faculty become more productive.

In addition to reforming its curriculum, Rensselaer is 